\title{
Review on Molecular and Chemopreventive Potential of Nimbolide in Cancer
}

\author{
Perumal Elumalai*, Jagadeesan Arunakaran \\ Department of Endocrinology, Dr. ALM Post Graduate Institute of Basic Medical Sciences, \\ University of Madras, Chennai 600113, India
}

\begin{abstract}
Cancer is the most dreaded disease in human and also major health problem worldwide. Despite its high occurrence, the exact molecular mechanisms of the development and progression are not fully understood. The existing cancer therapy based on allopathic medicine is expensive, exhibits side effects; and may also alter the normal functioning of genes. Thus, a non-toxic and effective mode of treatment is needed to control cancer development and progression. Some medicinal plants offer a safe, effective and affordable remedy to control the cancer progression. Nimbolide, a limnoid derived from the neem (Azadirachta indica) leaves and flowers of neem, is widely used in traditional medical practices for treating various human diseases. Nimbolide exhibits several pharmacological effects among which its anticancer activity is the most promising. The previous studies carried out over the decades have shown that nimbolide inhibits cell proliferation and metastasis of cancer cells. This review highlights the current knowledge on the molecular targets that contribute to the observed anticancer activity of nimbolide related to induction of apoptosis and cell cycle arrest; and inhibition of signaling pathways related to cancer progression.
\end{abstract}

Keywords: apoptosis, cell proliferation, chemoprevention, neoplasm metastasis, nimbolide

\section{Introduction}

Cancer is the most dangerous disease of human and a major health problem worldwide [1]. Preclinical studies have shown that cancer is a large group of diseases characterized by the uncontrolled cell growth and spread of abnormal cells. Over the past quarter of a century, an outstanding progress in understanding of the proteins involved in cancer progression has grown, providing chances for identifying new targets for anti-cancer therapy $[2,3]$. Present modes of treatment based on synthetic drugs have limited potential, because they are toxic and expensive and also alter cell signaling pathways. Natural drugs that are safe, affordable, and effective are needed to control cancer development and progression. Natural products have been used for thousands of years in the management of several diseases including various types of cancer [4]. Nimbolide was first derived from the leaves and flowers of neem. Neem (Azadirachta indica), is a traditional medicinal plant of the Meliaceae family widely distributed in Asia, Africa and other tropical parts of the world. All parts of the neem tree offer amazing potential for medicinal, agricultural and industrial exploitation and have been evaluated for antiinflammatory, antipyretic, antihistamine, antifungal, antitubercular, antiprotozoal, vasodilatory, antimalarial, diuretic, spermicidal, antiarthritic, insect repellent, antifeedant, and antihormonal activities [5].

Studies of extracts from all major parts of neem plant including the leaves, flowers, fruits, and seeds, have shown promising chemopreventive and therapeutic effects in pre-clinical research [6]. Extracts of neem leaf have been reported to be non-toxic and non-mutagenic and are found to possess immunomodulatory as well as anti-inflammatory and anticarcinogenic properties [7]. There are many studies showing the ethanolic extract of neem leaves to possess anticancer activity. Ethanolic neem leaf extract (ENLE) exhibited anticancer activity against N-methyl-N'-nitro-Nnitrosoguanidine-induced oxidative stress and gastric carcinogenesis [8]. ENLE induces apoptosis in a prostate cancer cell line (PC-3) by up-regulating the pro-apoptotic 
protein Bax and decreasing the level of $\mathrm{Bcl}-2$ protein resulting in DNA fragmentation in prostate cancer cells $[9,10]$. Many bioactive compounds are isolated from this plant among which, nimbolide belongs to the limonoid group. It is the major component of the leaves of $A$. indica.

Nimbolide (5,7,4'-trihydroxy-3',5'-diprenylflavanone), is a tetranortriterpenoid with a, $\beta$-unsaturated system and $\delta$-lactonic ring (Fig. 1) [11]. It has been shown to exhibit numerous types of biological activities, including, antimalarial [12], anti-bacterial activity [13], anti-feedent, [14] and anticancer activities [15-19]. Literature evidence reveals that $\alpha, \beta$-unsaturated ketone structural element is responsible for the anticancer activity of nimbolide [20, 21].

\section{Mechanism of Action of Nimbolide in Cancer Prevention}

Cancers are abnormal cell growth caused by genomic modification. So, any agent that has anti-cancer activity

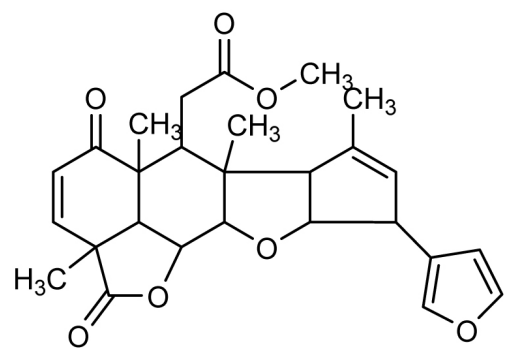

Fig. 1. Structure of nimbolide. Molecular formula, $\mathrm{C}_{27} \mathrm{H}_{30} \mathrm{O}_{7}$; molecular weight, 466.5; appearance, white to off-white solid. either protects genetic material from alterations or kills the genetically altered cancer cells. The active component nimbolide from neem acts on cancer cells and kill them by altering the several molecular pathways. The cytotoxicity of nimbolide has been widely studied over the last several years in a large variety of cancer cell lines [22]. It was reported recently that nimbolide inhibited cancer progression by influencing multiple mechanisms, including prevention of procarcinogen activation and oxidative DNA damage, upregulation of antioxidant and induction of apoptosis, inhibition of tumor cell proliferation, invasion, angiogenesis, and metastasis [19, 23-26]. The potential mechanisms of cancer prevention by nimbolide are described below and summarized in Fig. 2.

\section{Inhibition of Cancer Cell Proliferation and Growth}

Tumorigenesis and cancer progression are thought to be the result of some changes in different types of genetic pathways [27, 28]. Nimbolide, a chief constituent of neem, shows a vital role in cancer prevention and treatment through the modulation of various biological activities, including molecular cascades. However, understanding the mechanism of action of nimbolide in the activation or inactivation of genetic pathways will provide significant information to develop therapeutic approaches to manage various types of cancers.

Nimbolide induces in vitro cytotoxic activity against human cancer cell lines [20]. Nimbolide decreased cell viability, with an IC50 ranging from 4 to $10 \mu \mathrm{M}$ and averaging

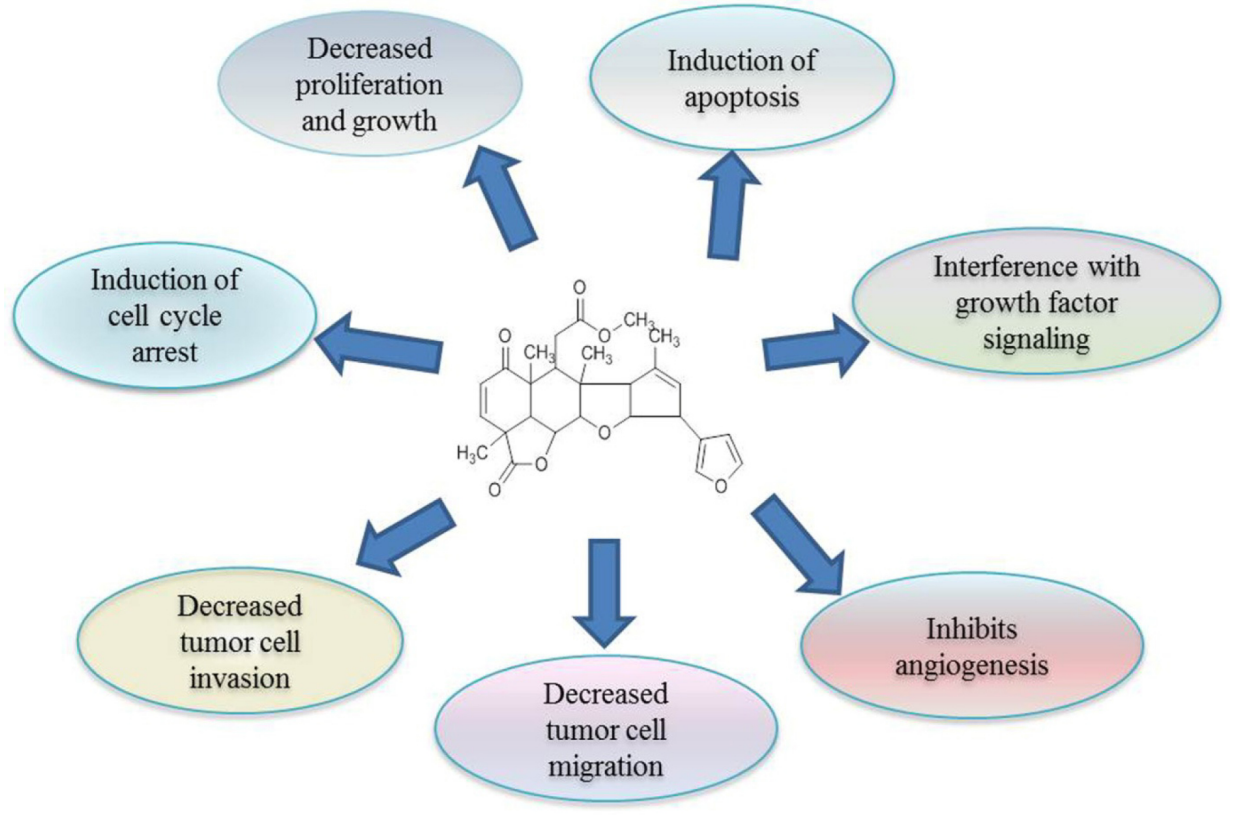

Fig. 2. Potential mechanisms of cancer prevention by nimbolide. 
$6 \mu \mathrm{M}$ for the neuroblastoma (NE-115) and osteosarcoma (143B) cell lines [15]. Sastry et al. [21] have tested the in vitro cytotoxicity of nimbolide against a panel of human cancer cell lines. Treatment of cells with $0.5-5.0 \mu \mathrm{M}$ nimbolide resulted in growth inhibition of the U937, HL-60, THP1, and B16 cell lines. It has been shown to interfere with the expression of cell survival proteins (Bcl-2, Bcl-xL, IAP-1, and IAP-2), proliferation (cyclin D1), invasion (matrix metalloproteinase [MMP]-9), and angiogenesis (vascular endothelial growth factor [VEGF]) by inhibiting inhibitor of $\kappa b$ (Iкb) kinase (IKK)/nuclear factor kappa B (NF-kB) [16]. Nimbolide treatment to human colon carcinoma (HT-29) cells at $2.5-10 \mu \mathrm{M}$ resulted in moderate to very strong growth inhibition [29]. Nimbolide significantly inhibited cell viability, with IC50 values of $4.0 \mu \mathrm{M}$ and $2.7 \mu \mathrm{M}$ for 24 and $48 \mathrm{~h}$, respectively, in MCF-7 cells and $6.0 \mu \mathrm{M}$ and $3.2 \mu \mathrm{M}$ for 24 and $48 \mathrm{~h}$, respectively, in MDA-MB-231 cells [30].

The insulin-like growth factor (IGF) system is involved in the proliferation, survival, and migration of tumor cells. IGF-I receptor (IGF-IR) is a receptor tyrosine kinase that is overexpressed in about $70 \%$ of breast cancers [31, 32]. It is established that the consequences of IGF-IR activation by its ligands result in the recruitment of major adapter signaling proteins, such as src/collagen homology proteins, which lead to interaction with Grb2/Sos [33]. Recruitment of these molecules activates two distinct signal transduction pathways. One pathway activates Ras, Raf, and mitogen-activated protein kinase (MAPK), resulting in the transcription of genes that drive proliferation, and the other pathway involves phosphoinositide 3-kinase (PI3K)/Akt, which are responsible for cell survival and anti-apoptotic signal transduction [34]. Downregulation of these molecules will give rise to inhibition of cell survival, invasion, and induction of apoptosis.

Aberrant activation of PI3K/Akt signaling has been associated with the development and progression of many cancers [35], making this pathway an attractive target for therapeutic strategies. The increase in p-Akt level in breast tumor samples correlates with a poor prognosis $[36,37]$ and predicts a worse outcome among endocrine-treated patients [38]. The major inhibitor of Akt is the dual-specificity protein and lipid phosphatase, phosphatase tensin homolog deleted on chromosome 10 (PTEN) that counteracts the PI3K-dependent Akt activation by dephosphorylating the D3 position of PIP3 [39]. PTEN activity is frequently lost by mutations, deletions or promoter methylation silencing in many primary and metastatic human cancers $[40,41]$. The inhibition of PI3K/Akt and activation of the PTEN pathway constitute a good strategy in the prevention of cancer.

The recent findings of Karkare et al. [42] proved that nimbolide suppresses glioblastoma viability and detains tumor growth by inhibiting CDK4/6 activity, leading to retinoblastoma hypophosphorylation and cell cycle arrest and by inhibiting growth factor pathways that are hyperactivated in glioblastoma, including the PI3K-Akt, MAPK, and JAK-STAT pathways [42]. It has been reported that decreased IGF-IR $\beta$ expression and increased IGFBP-3 expression are observed in nimbolide-treated breast cancer cells. The protein expression of the IGF signaling molecules IRS-2, PI3K, pAkt, Ras, Raf, MEK, and MAPK was

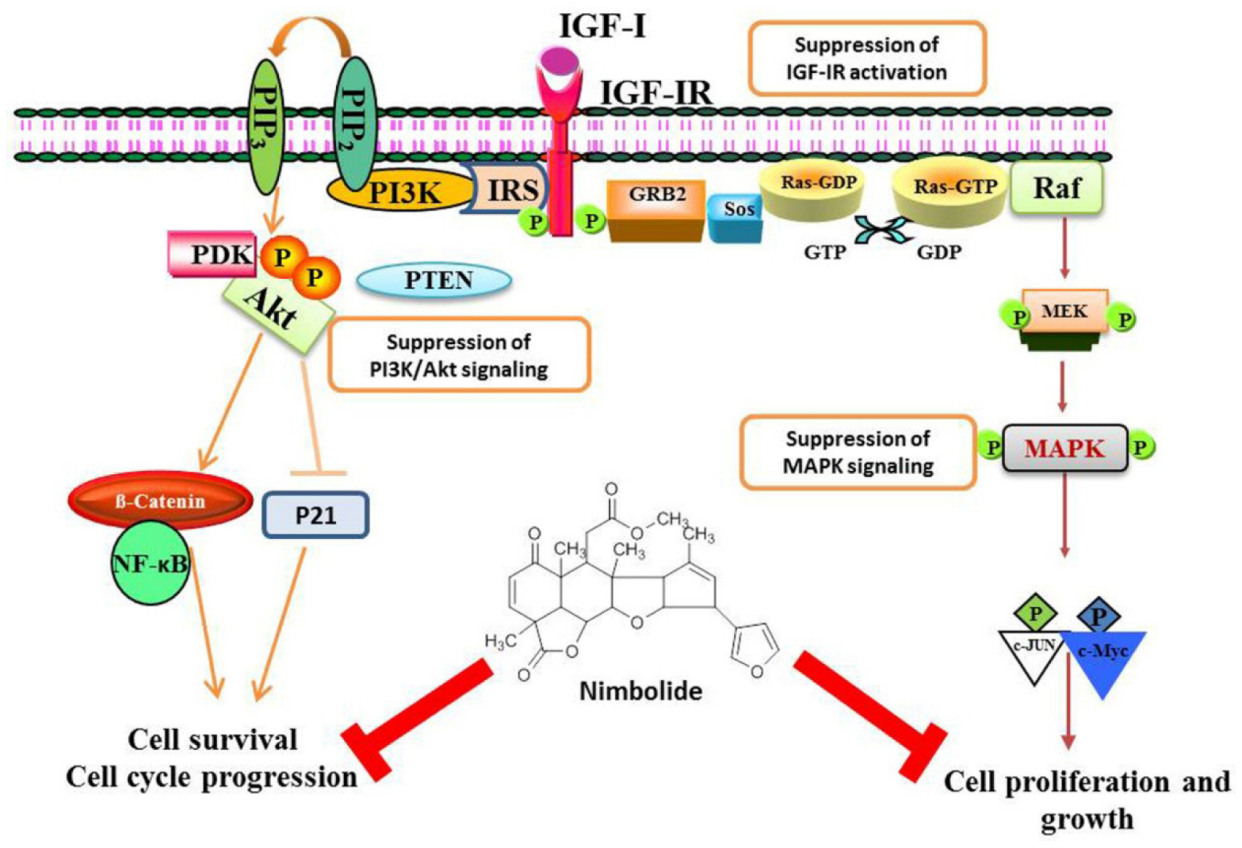

Fig. 3. Detailed scheme of the growth factor signalling pathways targeted by nimbolide in cancer cells. Nimbolide strongly inhibits IGF-IR and also affects downstream signalling via the MAPK (ERK) and PI3K/Akt. Transcription factors like NF- $\mathrm{kB}$, c-Myc, and $\beta$-catenin consequently cannot be activated, thus modulating target gene expression. As most of the target genes are implicated in cell cycle regulation and proliferation, the cancer cells are finally blocked in cell cycle progression. ERK, extracellularsignal-regulated kinase; IGF-IR, insulin-like growth factor 1 receptor; MAPK, mitogen-activated protein ki-

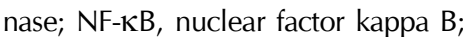
PI3K, phosphoinositide 3-kinase; PTEN, phosphatase tensin homolog deleted on chromosome 10 . 
significantly decreased in nimbolide-treated cells. This is further supported by a significant increase in the protein expression of PTEN upon nimbolide treatment in breast cancer cell lines (Fig. 3). Thereby, nimbolide inhibits the cell survival and proliferation of breast cancer and prostate cancer cells [19, 43].

\section{The Effects of Nimbolide on NF-kB Signaling}

NF- $\mathrm{kB}$ comprises a family of transcription factors involved in the regulation of a wide variety of biological responses. NF-kB has a well-known function in the regulation of immune responses and inflammation, but growing evidence supports a major role in oncogenesis. $\mathrm{NF}-\kappa \mathrm{B}$ regulates the expression of genes involved in many processes that play a key role in the development and progression of cancer, such as proliferation, migration, and apoptosis [44, 45]. This transcription factor is localized in

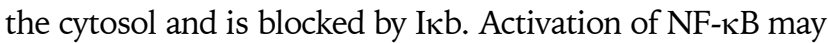
result from different signaling pathways triggered by a variety of cytokines, growth factors, and tyrosine kinases [44].

Recently, it was studied that nimbolide exerts potent anticancer effects in HepG2 cells by inhibiting NF-кB activation and its downstream events, such as activation of the Wnt/ $\beta$-catenin pathway and apoptosis evasion. Inhibitors of NF- $\mathrm{kB}$ which can block several signalling pathway, have developed as a successful candidates for novel anticancer regimens. Thus, nimbolide, by targeting multiple components of the NF- $\mathrm{kB}$ signaling pathway to inhibit tumor progression, is a promising agent for cancer prevention and therapy [17]. Gupta et al. [16] found that suppression of NF-KB activation by nimbolide was caused by inhibition of IKK, which led to suppression of IкB phosphorylation and degradation, nuclear translocation, DNA binding, and gene transcription in myeloid and leukemic cells. Nimbolide significantly decreased the protein expression of IKK $\alpha$, IKK $\beta$, and NF- $\mathrm{KB}$ in breast cancer cell lines [46].

\section{Nimbolide Inhibits Cancer Cell Metastasis}

Metastasis is the process by which a cancer cell leaves the primary tumor, travels to a distant site via the circulatory system, and begins a secondary tumor. In order to metastasize, cancer cells must invade through the basement membrane and the extracellular matrix (ECM). Proteolysis of the ECM is an important step in metastasis, and the process is associated with the upregulated production and activity of several ECM-degrading proteases. The matrix metalloproteinases (MMPs) constitute a family of struc- turally related, zinc-dependent endopeptidases that are capable of degrading the protein components of the ECM and basement membrane and release growth factors from ECM stores [47, 48]. MMP activity is regulated by specific inhibitors, the tissue inhibitors of MMP (TIMPs). Activation of chemokines and the urokinase plasminogen activator (uPA)/uPA receptor (uPAR) system is also a central mediator of tumor-cell migration and invasion, and IGF-I signaling can influence the UPAR pathway.

Chemokines are chemotactic cytokines that cause the directed migration of leukocytes and are induced by inflammatory cytokines, growth factors, and pathogenic stimuli. Chemokine signaling results in the transcription of target genes that are involved in cell invasion, motility, and survival. The upregulation of chemokine molecules in tumor biology as compared with "normal" cells confers chemokines as "a magic bullet," as targeting them can potentially hit cancer cells and their metastasis, leaving non-affected cells unharmed [49]. The expression of the chemokines CCL2, CXCL12, and CXCL8 and their receptors CCR2, CXCR1, CXCR2, and CXCR4 is significantly decreased in nimbolide-treated breast cancer cell lines [46].

uPA is a serine protease that is involved in cancer progression, mainly invasion and metastasis [50]. uPA can be observed as a multifunctional protein that is involved in both proteolysis and signal transduction [51]. Recently, nimbolide has been shown to interfere with the expression of NF-kB-regulated proteins, like Bcl-2, cyclooxygenase 2, MMP-9, and VEGF, by inhibiting IKK. Therefore, it is likely that nimbolide will interfere with cell migration invasion and angiogenesis [29]. The neem limonoids azadirachtin and nimbolide inhibit hamster cheek pouch carcinogenesis by prevention of procarcinogen activation and oxidative DNA damage, upregulation of antioxidants and carcinogen detoxification enzymes, and inhibition of tumor invasion and angiogenesis [24]. The protein expression of MMP-2 and -9 is significantly decreased, and TIMP-2 expression is increased in nimbolide-treated breast cancer cells [46]. Other studies also reported that the protein expression and activity of MMP-2 and -9 were significantly decreased in myeloid leukemia cell lines [16] and colon cancer cells [29]. Limonoid-treated xenografts exhibited significant downregulation in the expression of proteins involved in tumor cell survival (Bcl-2, Bcl-xL, c-IAP-1, survivin, and Mcl-1), proliferation (c-Myc and cyclin D1), invasion (MMP-9, intercellular adhesion molecule 1), metastasis (CXCR4), and angiogenesis (VEGF) [26]. The migration and invasive potential of the MCF-7 and MDA-MB-231 cell lines were considerably suppressed upon nimbolide treatment. The results showed that nimbolide downregulated the expression of UPA, UPAR, chemokines, phopho-epidermal growth 
factor receptor, vascular endothelial growth factor, NF- $\mathrm{kB}$, IKK $\alpha$, IKK $\beta$, MMP-2, and MMP-9 and upregulated the expression of TIMP-2, suggesting that nimbolide inhibits angiogenesis and metastasis of breast cancer [46].

\section{Inhibition of Cell Cycle and Induction of Apoptosis by Nimbolide}

The loss of the ability to regulate the cell-cycle is characteristic of cancer cells and results in uncontrollable proliferation. Processing cells through the first gap (G) phase of the cell cycle is a step that is frequently disordered in cancer [52]. Nimbolide has been investigated in different studies for its ability to mediate cell cycle arrest. In many in vitro and in vivo studies, nimbolide has shown cell cycle-regulatory effects $[18,25,53,54]$. It has been reported that nimbolide inhibits cell proliferation by interfering with cell cycle kinetics by inducing G0/G1 and S phase arrest, primarily caused through the repression of cyclin $\mathrm{A} /$ cyclin D1 [16, 54, 55].

In another interesting molecular study, a Japanese group has proved that nimbolide, a triterpenoid present in certain edible parts of $A$. indica, arrested HT-29 cells in the G2/M and G0/G1 stages apparently through upregulation of p21, which is a well-known downstream effector of the p53. p53 is a very important anticancer protein that regulates a large number of genes that are involved in cancer progression. Nimbolide has also been shown to upregulate cyclin D2 and CDK2 and to suppress the expression of cyclin A, cyclin E, $\mathrm{CDK} 2$, and Rad17 at the same time [53]. Flow cytometric analysis of U937 cells showed that nimbolide treatment (1$2.5 \mu \mathrm{M}$ ) resulted in cell cycle disruption by decreasing the number of cells in G0/G1 phase, with initial increases in $S$ and $\mathrm{G} 2 / \mathrm{M}$ phases. It is shown that nimbolide can affect cell cycle progression and induce apoptosis in colon cancer, oral carcinoma, and cervical cancer $[18,25,55]$. Nimbolide significantly suppressed the viability of HeLa cells in a dosedependent manner by inducing cell cycle arrest at G0/G1 phase, accompanied by p21 accumulation and downregulation of the cell cycle regulatory proteins cyclin B, cyclin D1, and proliferating cell nuclear antigen (PCNA) [55].

Nimbolide treatment results in the accumulation of cells in G0/G1 phase and decreased in S-phase by up regulating p21 and downregulating the cell cycle-regulatory proteins cyclins and PCNA. Cyclin D1 is known as a proto-oncogene whose gene amplification and protein overexpression of which are frequently observed in tumor cells. The activated cyclin D1/CDK4 and cyclin D1/CDK6 complex phosphorylates the retinoblastoma protein to induce the expression of target genes essential for $\mathrm{S}$ phase entry, facilitating the progression from G1 to $S$ phase [56]. Cyclin B1 is a
G2/mitotic-specific protein that plays a role in the initiation of mitosis and tumorigenesis [57]. It was reported that cyclin B1 depletion inhibits proliferation and induces apoptosis in human tumor cells [57]. Nimbolide treatment decreases cyclin (A1, B1, C, D1, and E1) expression in breast cancer cells. $\mathrm{p} 21^{\text {Wafl/Cip1 }}$, originally identified as an inhibitor of the cyclin/CDK complexes, has also been shown to have a role as an adaptor protein that assembles and promotes the kinase activity of cyclin D/CDK4 complexes [58]. The level of p21 was significantly increased in nimbolide-treated breast cancer cell lines. PCNA, a cofactor for DNA polymerase $\delta$, plays a central role in cell cycle progression [59]. PCNA is involved in a wide range of cellular functions, including DNA replication, repair, and epigenetic maintenance, and is often used as a diagnostic and prognostic marker. The protein expression of PCNA is decreased in nimbolidetreated breast cancer cells [19]. Nimbolide directly inhibited CDK4/CDK6 kinase activity, leading to hypophosphorylation of the retinoblastoma protein, cell cycle arrest at G1-S, and cell death [42]. In animal tumor models, nimbolide (100 $\mu \mathrm{g} / \mathrm{kg}$ ) has been shown to exhibit chemopreventive activity against 7,12-dimethylbenzanthracene (DMBA) 3-induced hamster buccal pouch carcinogenesis by downregulating proteins involved in cell cycle progression and transduce apoptosis by both the intrinsic and extrinsic pathways [25]

Apoptosis, or programmed cell death, is essential for the maintenance of development and homeostasis of multicellular organisms by eliminating superfluous or unwanted cells. Any alteration or change in the normal process of apoptosis may increase cell survival and support tumor development and progression [60]. The extrinsic and intrinsic pathways represent the two major well-studied apoptotic processes. Inefficient apoptosis is considered one of the hallmarks of tumorigenicity [61]. Moreover, induction of apoptosis is an important target for cancer therapy [62]. The extrinsic pathway is initiated by cell surface-expressed death receptors of the tumor necrosis factor superfamily. One of the central pathways of apoptosis is initiated by cytokines, such as tumor necrosis factor- $\alpha$, Fas ligand (FasL), and tumor necrosis factor- $\alpha$-related apoptosis-inducing ligand (TRAIL) [63]. The intrinsic pathway is initiated by anticancer drugs, growth factor withdrawal, or hypoxia or via induction of oncogenes. These stimuli induce permeabilization of the outer mitochondrial membrane and activate the mitochondrial pathway [64].

Caspases are a family of evolutionarily conserved cysteine proteases that play a essential role in the majority of apoptotic pathways. Death signals activate the proteolytic cascade of caspases through two main pathways: an extrinsic and intrinsic pathway [65]. Both pathways converge to the activation of caspase-3, the closer homolog of Caenor- 
habditis elegans CED-3 [66]. Caspase-3 activates downstream enzymes of the caspase family and contributes with them to generate the typical apoptotic cell death phenotype [67]. Harish Kumar et al. [25] reported that nimbolide transduces apoptosis by both the intrinsic and extrinsic pathways in DMBA-induced hamster buccal pouch carcinogenesis. Working on the choriocarcinoma (BeWo) cells, have shown that nimbolide, induces apoptosis through engagement of the mitochondrial pathway. The involvement of this pathway is based on the observation that nimbolide mediates the upregulation of Apaf1 and a caspase- 3 and decrease in the Bcl2/Bax ratio [54].

Nimbolide sensitizes human colon cancer cell lines (HCT116 and HT-29) to TRAIL through reactive oxygen speciesand Erk-dependent up-regulation of death receptors, p53, and Bax. A normal breast cell line (MCF-10A) and breast cancer cell lines (MCF-7) were treated with nimbolide (1-5 $\mu \mathrm{M})$ for $6 \mathrm{~h}$, followed by TRAIL for $24 \mathrm{~h}$. The results indicated that whereas nimbolide and TRAIL alone were minimally effective in inducing apoptosis in MCF-7 cells, the combination of both enhanced the number of apoptotic cells to $42 \%$. Conversely, the combination of nimbolide and TRAIL was unable to evoke apoptosis in the normal breast cell line. The results showed a lack of DR5 and DR4 induction in MCF-10A cells by nimbolide, whereas a dose-dependent induction of these receptors was observed in MCF-7 cells [68]. The decreased expression of Bcl-2 and increased expression of bax, cytochrome c, Smac, and caspases, together with changes in nuclear morphology and mitochondrial transmembrane potential, seen in nimbolide treatment and inhibition of NF- $\mathrm{\kappa B}$ activation by nimbolide, stimulate the intrinsic apoptotic pathway in HepG2 cells [17]. In another study, nimbolide repressed cell proliferation by inhibiting the IGF1/IGF-IR-PI3K/Akt pathway and induced apoptosis through the activation of both the extrinsic and intrinsic apoptotic pathways in prostate cancer cells [43].

Nimbolide also induced apoptosis in breast cancer cells by

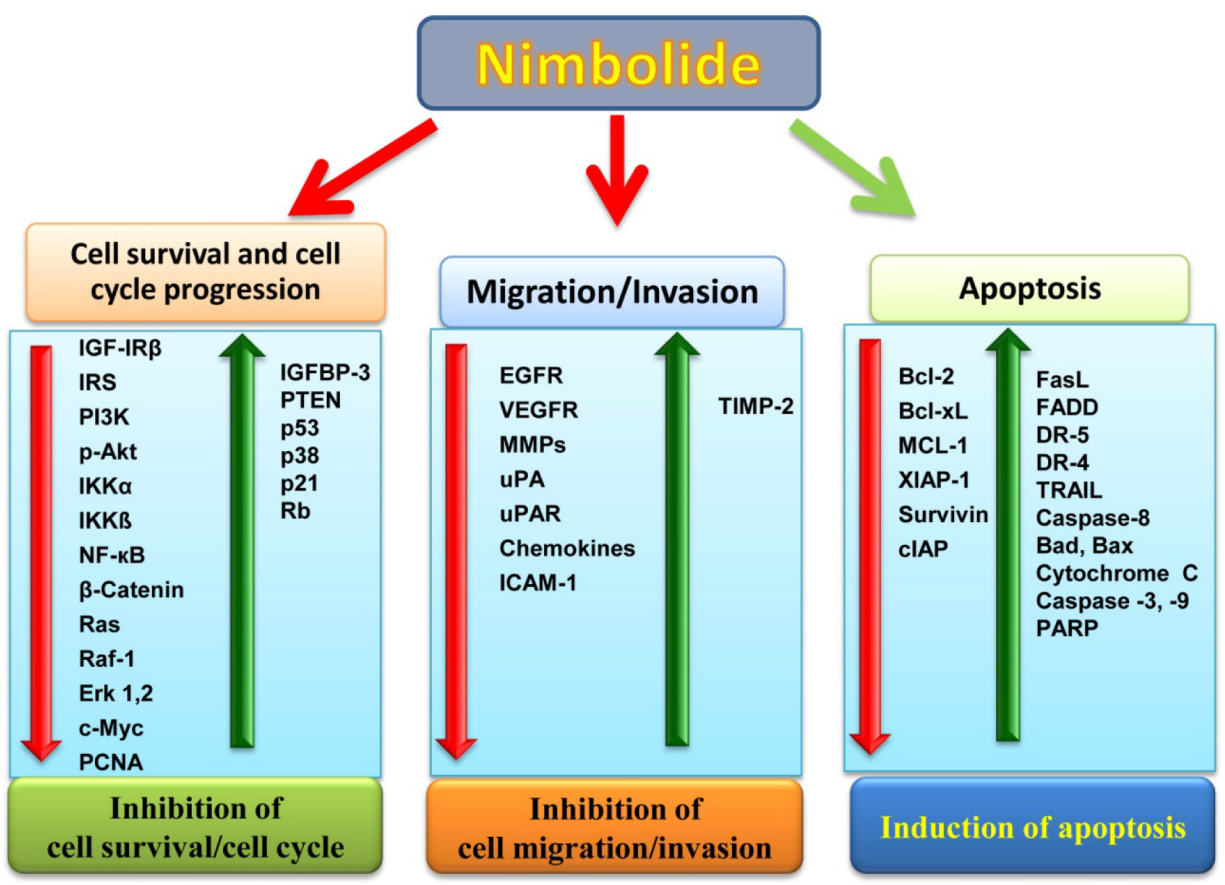

Fig. 4. Nimbolide shows an important role in cancer prevention via inhibition of cell survival, cell cycle progression, invasion, migration and induction of apoptosis. The diverse molecular targets influenced by nimbolide include the growth factors and their receptor, signaling molecules, transcription factors, protein kinases, enzymes and genes regulating cell proliferation and apoptosis. Red down arrow indicates that these molecules are down-regulated by nimbolide, whereas, green up arrow indicate that these molecules are up-regulated by nimbolide. $\mathrm{Bad}, \mathrm{Bcl}-2$-associated death promoter; Bax, Bcl-2-associated X protein; Bcl-2, B cell lymphoma 2; Bcl-xL, B-cell lymphoma-extra-large; DR-5, death receptor-5; EGFR, epidermal growth factor receptor; ERK, extracellular-signal-regulated kinase; FADD, Fas-associated death domain; FasL, Fatty acid synthase ligand; ICAM, Intercellular adhesion molecule; IGF-1, insulin-like growth factor 1; IGFBP-3, IGF-binding protein 3; IKK, IKB kinase; IRS, insulin receptor substrate; MCL-1, myeloid cell leukemia 1; MMPs, matrix metalloproteinases; NF- $\mathrm{KB}$, nuclear factor kappa B; PARP, poly(ADP) ribose polymerase; PCNA, proliferating cell nuclear antigen; PI3K, phosphoinositide 3-kinase; PTEN, phosphatase tensin homolog deleted on chromosome 10; Rb, retinoblastoma; TIMP, tissue inhibitor of matrix metalloproteinase; TRAIL, tumor necrosis factor apoptosis inducing ligand; VEGF, vascular endothelial growth factor; VEGFR, vascular endothelial growth factor receptor; XIAP, X-linked inhibitor of apoptosis protein; UPA, urokinase plasminogen antigen; UPAR, urokinase plasminogen antigen receptor. 
upregulating pro-apoptotic protein (Bad, Bax, FasL, FADD, TRAIL, and cytochrome c) expression and down-regulating anti-apoptotic proteins (Bcl-2, Bcl-xL, Mcl-1, and XIAP-1). Nimbolide activates caspase- $3,-8$, and -9 , which favors the cleavage of poly(ADP) ribose polymerase into 115- and $85-\mathrm{kDa}$ peptides, thus inducing apoptosis in breast cancer cell lines. Further, the nimbolide-induced apoptotic cells were detected using DAPI and $\mathrm{AO} / \mathrm{EtBr}$ dual staining. After treatment with nimbolide, the cells exhibited the typical morphological changes associated with apoptosis: cell shrinkage, nuclear condensation, and membrane blebbing [30]. Activation of caspase- $3,-8$, and -9 , suggests that nimbolide potentiated both the extrinsic and intrinsic pathways of apoptosis in human breast and colon cancer cells $[68,30]$. The overview of all of the signaling molecules modulated by nimbolide is shown in Fig. 4 .

\section{Conclusion and Future Perspectives}

Cancer has continually been the leading cause of death worldwide for decades. Thus, researchers have actively devoted themselves to studying cancer therapeutics. The present mode of treatment based on chemotherapy and radiotherapy is very expensive and also exhibits serious side effects in human beings. Keeping in view the significance of herbs, this review is written to show the role of nimbolide in the prevention of various types of cancer through the activation or inactivation of various signaling pathways. These reported features, combined with the absence of side effects and being inexpensive and easy to access, neem and its constituent nimbolide may be proved very effective therapeutics in the management of cancers. Nimbolide is a potential chemopreventive agent that is able to suppress multiple signaling pathways involved in carcinogenesis and hence is an attractive candidate for further research. Currently, nimbolide is undergoing extensive research to determine the dose efficacy and administration form that could enhance its bioavailability and chemopreventive properties. How nimbolide mediates all of these effects is not completely understood. However, most of the anticancer activities assigned to nimbolide have been based on in vitro studies. While in vitro studies predominantly established the anti-cancer effects of nimbolide on cancer cells, its efficiency in vivo has still to be proven.

\section{Acknowledgments}

The financial support from the Council for Scientific and Industrial Research (India) in the form of a Senior Research Fellowship (CSIR-SRF) to P. Elumalai is greatly acknowledged.

\section{References}

1. Hanahan D, Weinberg RA. Hallmarks of cancer: the next generation. Cell 2011;144:646-674.

2. Alyasiri NS, Mehdi SJ, Alam MS, Ali A, Mandal AK, Gupta S, et al. PTEN-mediated AKT activation contributes to the reduced apoptosis among Indian oral squamous cell carcinoma patients. J Cancer Res Clin Oncol 2012;138:103-109.

3. Singh SR. Cancer stem cells: recent developments and future prospects. Cancer Lett 2013;338:1-2.

4. Kaefer CM, Milner JA. The role of herbs and spices in cancer prevention. J Nutr Biochem 2008;19:347-361.

5. Biswas K, Chattopadhyay I, Banerjee RK, Bandyopadhyay U. Biological activities and medicinal properties of neem (Azadirachta indica). Curr Sci 2002;82:1336-1345.

6. Paul R, Prasad M, Sah NK. Anticancer biology of Azadirachta indica L (neem): a mini review. Cancer Biol Ther 2011;12:467476.

7. Subapriya R, Nagini S. Medicinal properties of neem leaves: a review. Curr Med Chem Anticancer Agents 2005;5:149-146.

8. Subapriya R, Nagini S. Ethanolic neem leaf extract protects against $\mathrm{N}$-methyl -N'-nitro-N-nitrosoguanidine-induced gastric carcinogenesis in Wistar rats. Asian Pac J Cancer Prev 2003;4:215-223.

9. Kumar S, Suresh PK, Vijayababu MR, Arunkumar A, Arunakaran J. Anticancer effects of ethanolic neem leaf extract on prostate cancer cell line (PC-3). J Ethnopharmacol 2006;105:246-250.

10. Gunadharini DN, Elumalai P, Arunkumar R, Senthilkumar K, Arunakaran J. Induction of apoptosis and inhibition of $\mathrm{PI} 3 \mathrm{~K} /$ Akt pathway in PC-3 and LNCaP prostate cancer cells by ethanolic neem leaf extract. J Ethnopharmacol 2011;134:644650 .

11. Anitha G, Raj JJ, Krishnan VR, Narasimhan S, Solomon KA, Rajan SS. Semi-synthetic modification of nimbolide to 6-homodesacetylnimbin and 6-desacetylnimbin and their cytotoxic studies. J Asian Nat Prod Res 2007;9:73-78.

12. Rochanakij S, Thebtaranonth Y, Yenjai C, Yuthavong Y. Nimbolide, a constituent of Azadirachta indica, inhibits Plasmodium falciparum in culture. Southeast Asian J Trop Med Public Health 1985;16:66-72.

13. Rojanapo W, Suwanno S, Somjaree R, Glinsukon T, Thebtaranont Y. Mutagenic and antibacterial activity testing of nimbolide and nimbic acid. J Sci Soc Thailand 1985;11:177181.

14. Suresh G, Gopalakrishnan G, Wesley SD, Pradeep Singh ND, Malathi R, Rajan SS. Insect antifeedant activity of tetranortriterpenoids from the Rutales: a perusal of structural relations. J Agric Food Chem 2002;50:4484-4490.

15. Cohen E, Quistad GB, Casida JE. Cytotoxicity of nimbolide, epoxyazadiradione and other limonoids from neem insecticide. Life Sci 1996;58:1075-1081.

16. Gupta SC, Prasad S, Reuter S, Kannappan R, Yadav VR, Ravindran J, et al. Modification of cysteine 179 of IkappaBalpha kinase by nimbolide leads to down-regulation of NF-kappaB-regulated cell survival and proliferative proteins and sensitization of tumor cells to chemotherapeutic agents. 
J Biol Chem 2010;285:35406-35417.

17. Kavitha K, Vidya Priyadarsini R, Anitha P, Ramalingam K, Sakthivel R, Purushothaman G, et al. Nimbolide, a neem limonoid abrogates canonical NF-kappaB and Wnt signaling to induce caspase-dependent apoptosis in human hepatocarcinoma (HepG2) cells. Eur J Pharmacol 2012;681:6-14.

18. Roy MK, Kobori M, Takenaka M, Nakahara K, Shinmoto H, Isobe $S$, et al. Antiproliferative effect on human cancer cell lines after treatment with nimbolide extracted from an edible part of the neem tree (Azadirachta indica). Phytother Res 2007; 21:245-250.

19. Elumalai P, Arunkumar R, Benson CS, Sharmila G, Arunakaran J. Nimbolide inhibits IGF-I-mediated PI3K/Akt and MAPK signalling in human breast cancer cell lines (MCF-7 and MDA-MB-231). Cell Biochem Funct 2014;32: 476-484.

20. Kigodi PG, Blaskó G, Thebtaranonth Y, Pezzuto JM, Cordell GA. Spectroscopic and biological investigation of nimbolide and 28-deoxonimbolide from Azadirachta indica. J Nat Prod 1989;52:1246-1251.

21. Sastry BS, Suresh Babu K, Hari Babu T, Chandrasekhar S, Srinivas PV, Saxena AK, et al. Synthesis and biological activity of amide derivatives of nimbolide. Bioorg Med Chem Lett 2006;16:4391-4394.

22. Bodduluru LN, Kasala ER, Thota N, Barua CC, Sistla R. Chemopreventive and therapeutic effects of nimbolide in cancer: the underlying mechanisms. Toxicol In Vitro 2014;28:10261035.

23. Sritanaudomchai $H$, Kusamran T, Kuakulkiat W, Bunyapraphatsara N, Hiransalee A, Tepsuwan A, et al. Quinone reductase inducers in Azadirachta indica A. Juss flowers, and their mechanisms of action. Asian Pac J Cancer Prev 2005;6:263-269.

24. Priyadarsini RV, Manikandan P, Kumar GH, Nagini S. The neem limonoids azadirachtin and nimbolide inhibit hamster cheek pouch carcinogenesis by modulating xenobiotic-metabolizing enzymes, DNA damage, antioxidants, invasion and angiogenesis. Free Radic Res 2009;43:492-504.

25. Harish Kumar G, Vidya Priyadarsini R, Vinothini G, Vidjaya Letchoumy P, Nagini S. The neem limonoids azadirachtin and nimbolide inhibit cell proliferation and induce apoptosis in an animal model of oral oncogenesis. Invest New Drugs 2010;28: 392-401.

26. Gupta SC, Prasad S, Sethumadhavan DR, Nair MS, Mo YY, Aggarwal BB. Nimbolide, a limonoid triterpene, inhibits growth of human colorectal cancer xenografts by suppressing the proinflammatory microenvironment. Clin Cancer Res 2013;19:4465-4476.

27. Rahmani A, Alzohairy M, Mandal AK, Rizvi MA. Expressional evaluation of androgen receptor in transitional cell carcinoma of urinary bladder patients. Br J Med Med Res 2011;1:233-238.

28. Babiker AY, Rahmani AH, Abdalaziz MS, Albutti A, Aly SM, Ahmed HG. Expressional analysis of p16 and cytokeratin 19 protein in the genesis of oral squamous cell carcinoma patients. Int J Clin Exp Med 2014;7:1524-1530.

29. Babykutty S, S PP, J NR, Kumar MA, Nair MS, Srinivas P, et al. Nimbolide retards tumor cell migration, invasion, and angiogenesis by downregulating MMP-2/9 expression via inhibit- ing ERK1/2 and reducing DNA-binding activity of NF-kappaB in colon cancer cells. Mol Carcinog 2012;51:475-490.

30. Elumalai P, Gunadharini DN, Senthilkumar K, Banudevi S, Arunkumar R, Benson CS, et al. Induction of apoptosis in human breast cancer cells by nimbolide through extrinsic and intrinsic pathway. Toxicol Lett 2012;215:131-142.

31. Nielsen TO, Andrews HN, Cheang M, Kucab JE, Hsu FD, Ragaz J, et al. Expression of the insulin-like growth factor I receptor and urokinase plasminogen activator in breast cancer is associated with poor survival: potential for intervention with 17-allylamino geldanamycin. Cancer Res 2004;64:286-291.

32. Sachdev D, Hartell JS, Lee AV, Zhang X, Yee D. A dominant negative type I insulin-like growth factor receptor inhibits metastasis of human cancer cells. J Biol Chem 2004;279:50175024.

33. Pollak MN, Schernhammer ES, Hankinson SE. Insulin-like growth factors and neoplasia. Nat Rev Cancer 2004;4:505-518.

34. Manning BD, Cantley LC. AKT/PKB signaling: navigating downstream. Cell 2007;129:1261-1274.

35. Nicholson KM, Anderson NG. The protein kinase B/Akt signalling pathway in human malignancy. Cell Signal 2002;14: 381-395.

36. Tokunaga E, Kimura Y, Oki E, Ueda N, Futatsugi M, Mashino $\mathrm{K}$, et al. Akt is frequently activated in HER2/neu-positive breast cancers and associated with poor prognosis among hormone-treated patients. Int J Cancer 2006;118:284-289.

37. Bartlett JM, A'Hern R, Piper T, Ellis IO, Dowsett M, Mallon EA, et al. Phosphorylation of AKT pathway proteins is not predictive of benefit of taxane therapy in early breast cancer. Breast Cancer Res Treat 2013;138:773-781.

38. Pérez-Tenorio G, Stål O; Southeast Sweden Breast Cancer Group. Activation of AKT/PKB in breast cancer predicts a worse outcome among endocrine treated patients. $\mathrm{Br}$ J Cancer 2002;86:540-545.

39. Vazquez F, Sellers WR. The PTEN tumor suppressor protein: an antagonist of phosphoinositide 3-kinase signaling. Biochim Biophys Acta 2000;1470:M21-M35.

40. Li J, Yen C, Liaw D, Podsypanina K, Bose S, Wang SI, et al. PTEN, a putative protein tyrosine phosphatase gene mutated in human brain, breast, and prostate cancer. Science 1997;275: 1943-1947.

41. Khan S, Kumagai T, Vora J, Bose N, Sehgal I, Koeffler PH, et al. PTEN promoter is methylated in a proportion of invasive breast cancers. Int J Cancer 2004;112:407-410.

42. Karkare S, Chhipa RR, Anderson J, Liu X, Henry H, Gasilina A, et al. Direct inhibition of retinoblastoma phosphorylation by nimbolide causes cell-cycle arrest and suppresses glioblastoma growth. Clin Cancer Res 2014;20:199-212.

43. Raja Singh P, Arunkumar R, Sivakamasundari V, Sharmila G, Elumalai P, Suganthapriya E, et al. Anti-proliferative and apoptosis inducing effect of nimbolide by altering molecules involved in apoptosis and IGF signalling via PI3K/Akt in prostate cancer (PC-3) cell line. Cell Biochem Funct 2014;32:217228.

44. Moynagh PN. The NF-kappaB pathway. J Cell Sci 2005; 118(Pt 20):4589-4592.

45. Kearns JD, Basak S, Werner SL, Huang CS, Hoffmann A. 
IkappaBepsilon provides negative feedback to control NFkappaB oscillations, signaling dynamics, and inflammatory gene expression. J Cell Biol 2006;173:659-664.

46. Elumalai P, Brindha Mercy A, Arunkamar R, Sharmila G, Bhat FA, Balakrishnan S, et al. Nimbolide inhibits invasion and migration, and down-regulates uPAR chemokine gene expression, in two breast cancer cell lines. Cell Prolif 2014;47:540-552.

47. Sachdev D. Regulation of breast cancer metastasis by IGF signaling. J Mammary Gland Biol Neoplasia 2008;13:431-441.

48. Bourboulia D, Stetler-Stevenson WG. Matrix metalloproteinases (MMPs) and tissue inhibitors of metalloproteinases (TIMPs): Positive and negative regulators in tumor cell adhesion. Semin Cancer Biol 2010;20:161-168.

49. Balkwill F. Cancer and the chemokine network. Nat Rev Cancer 2004;4:540-550.

50. Tang L, Han X. The urokinase plasminogen activator system in breast cancer invasion and metastasis. Biomed Pharmacother 2013;67:179-182.

51. Kong D, Li Y, Wang Z, Banerjee S, Sarkar FH. Inhibition of angiogenesis and invasion by 3,3'-diindolylmethane is mediated by the nuclear factor-kappaB downstream target genes MMP-9 and uPA that regulated bioavailability of vascular endothelial growth factor in prostate cancer. Cancer Res 2007;67: 3310-3319.

52. Sherr CJ. Cancer cell cycles. Science 1996;274:1672-1677.

53. Roy MK, Kobori M, Takenaka M, Nakahara K, Shinmoto H, Tsushida T. Inhibition of colon cancer (HT-29) cell proliferation by a triterpenoid isolated from Azadirachta indica is accompanied by cell cycle arrest and up-regulation of p21. Planta Med 2006;72:917-923.

54. Harish Kumar G, Chandra Mohan KV, Jagannadha Rao A, Nagini S. Nimbolide a limonoid from Azadirachta indica inhibits proliferation and induces apoptosis of human choriocarcinoma (BeWo) cells. Invest New Drugs 2009;27:246-252.

55. Priyadarsini RV, Murugan RS, Sripriya P, Karunagaran D, Nagini S. The neem limonoids azadirachtin and nimbolide induce cell cycle arrest and mitochondria-mediated apoptosis in human cervical cancer (HeLa) cells. Free Radic Res 2010;44: 624-634.
56. Takahashi-Yanaga F, Sasaguri T. GSK-3beta regulates cyclin D1 expression: a new target for chemotherapy. Cell Signal 2008;20:581-589.

57. Yuan J, Yan R, Krämer A, Eckerdt F, Roller M, Kaufmann M, et al. Cyclin B1 depletion inhibits proliferation and induces apoptosis in human tumor cells. Oncogene 2004;23:58435852.

58. LaBaer J, Garrett MD, Stevenson LF, Slingerland JM, Sandhu C, Chou HS, et al. New functional activities for the p21 family of CDK inhibitors. Genes Dev 1997;11:847-862.

59. Moldovan GL, Pfander B, Jentsch S. PCNA, the maestro of the replication fork. Cell 2007;129:665-679.

60. Danial NN, Korsmeyer SJ. Cell death: critical control points. Cell 2004;116:205-219.

61. Dowsett M, Smith IE, Ebbs SR, Dixon JM, Skene A, Griffith C, et al. Proliferation and apoptosis as markers of benefit in neoadjuvant endocrine therapy of breast cancer. Clin Cancer Res 2006; 12(3 Pt 2):1024s-1030s.

62. Fesik SW. Promoting apoptosis as a strategy for cancer drug discovery. Nat Rev Cancer 2005;5:876-885.

63. Ashkenazi A, Herbst RS. To kill a tumor cell: the potential of proapoptotic receptor agonists. J Clin Invest 2008;118:19791990.

64. Riedl SJ, Salvesen GS. The apoptosome: signalling platform of cell death. Nat Rev Mol Cell Biol 2007;8:405-413.

65. Johnstone RW, Ruefli AA, Lowe SW. Apoptosis: a link between cancer genetics and chemotherapy. Cell 2002;108:153164.

66. Porter AG, Jänicke RU. Emerging roles of caspase-3 in apoptosis. Cell Death Differ 1999;6:99-104.

67. Zhou Y, Peng Y, Mao QQ, Li X, Chen MW, Su J, et al. Casticin induces caspase-mediated apoptosis via activation of mitochondrial pathway and upregulation of DR5 in human lung cancer cells. Asian Pac J Trop Med 2013;6:372-378.

68. Gupta SC, Reuter S, Phromnoi K, Park B, Hema PS, Nair M, et al. Nimbolide sensitizes human colon cancer cells to TRAIL through reactive oxygen species- and ERK-dependent up-regulation of death receptors, p53, and Bax.J Biol Chem 2011;286: 1134-1146. 